\title{
Minute Ventilation Stabilization During All Pressure-Control / Support Mechanical Ventilation Modes
}

\author{
Peter CANDÍK ${ }^{1}$, Filip DEPTA ${ }^{1}, \breve{S}$ tefan IMRECZE $^{1}$, František SABOL ${ }^{2}$, Adrián KOLESAR ${ }^{2}$, \\ Monika JANKAJOVA ${ }^{3}$, Matúš PAULÍNY ${ }^{6}$, Janka BENOVA ${ }^{1}$, Katarína GALKOVÁ ${ }^{5}$, Viliam \\ DONIC ${ }^{4}$, Pavol TÖRÖK ${ }^{1,5}$
}

${ }^{1}$ Clinic of Anesthesiology and Intensive Medicine, East Slovakian Institute of Cardiovascular Diseases and Faculty of Medicine Safarik University, Kosice, Slovak Republic, ${ }^{2}$ Clinic of cardiac surgery, East Slovakian Institute of Cardiovascular Diseases and Faculty of Medicine Safarik University, Kosice, Slovak Republic, ${ }^{3}$ Clinic of Cardiology, East Slovakian Institute of Cardiovascular Diseases and Faculty of Medicine, Safarik University, Kosice, Slovak Republic, ${ }^{4}$ Department of Human Physiology, Faculty of Medicine, Safarik University, Kosice, Slovak Republic, ${ }^{5}$ Faculty of Social Sciences and Health Care, University of Constantine Philosopher, Nitra, Slovak Republic, ${ }^{6}$ Clinic of Anesthesiology and Intensive Medicine, Slovak Health University, Derer's Hospital, Bratislava, Slovakia

Received January 18, 2019

Accepted November 28, 2019

Epub Ahead of Print March 23, 2020

\section{Summary}

The main goal of our prospective randomized study was comparing compare the effectiveness of ventilation control method "Automatic proportional minute ventilation (APMV) "versus manually set pressure control ventilation modes in relationship to lung mechanics and gas exchange. 80 patients undergoing coronary artery bypass grafting (CABG) were randomized into 2 groups. 40 patients in the first group No. 1 (APMV group) were ventilated with pressure control (PCV) or pressure support ventilation (PSV) mode with APMV control. The other 40 patients (control group No.2) were ventilated with synchronized intermittent mandatory ventilation (SIMV-p) or pressure control modes (PCV) without APMV. Ventilation control with APMV was able to maintain minute ventilation more precisely in comparison with manual control $(p<0.01)$, similarly deviations of $\mathrm{ETCO}_{2}$ were significantly lower $(p<0.01)$. The number of manual corrections of ventilation settings was significantly lower when APMV was used $(p<0.01)$. The differences in lung mechanics and hemodynamics were not statistically significant. Ventilation using APMV is more precise in maintaining minute ventilation and gas exchange compared with manual settings. It required less staff intervention, while respiratory system mechanics and hemodynamics are comparable. APMV showed as effective and safe method applicable on top of all pressure control ventilation modes.

\section{Key words}

Artificial lung ventilation • Pressure controlled modes • Automatic proportional minute ventilation

\section{Corresponding author}

Viliam Donic, Department of Human Physiology, Faculty of Medicine, Safarik University, Trieda SNP 1, Kosice, Slovak Republic. Email: viliam.donic@upjs.sk

\section{Introduction}

Pressure-controlled mode represents the most prevalent method of artificial lung ventilation (ALV). Advantages of pressure-controlled ventilation are well known, e.g. patient safety, exponential flow curve ascent, peak-pressure stability etc. There are also a few disadvantages, e.g. gas exchange dependency from respiratory system mechanics (Campbell et al. 2002). Respiratory centre physiologically regulates components of respiratory system in a way to maintain adequate gas 
exchange with minimum energy expend, which was already demonstrated in clinical studies. Results confirm that the end parameter of regulation is minute ventilation (MV) or alveolar ventilation (VA) in order to maintain adequate gas exchange and thus acid-base balance (Török et al. 2015, Török et al. 2017).

Instability of alveolar ventilation in pressuresupported or controlled ventilation is mainly due to changes in respiratory system mechanics, patient's respiratory activity trigger and time constant of respiratory system (Török et al. 2001) (Candik et al. 2018). Even at constant pressure, changes in lung and chest wall compliance, airway and endotracheal tube (ETT) resistance, lead to changes in respiratory volume (VT) as well as MV. This could lead to severe hypo/hyperventilation (Grasso et al. 2000). Magnitude of $\mathrm{MV}$, or VA also consists of ventilatory drive of the patient and respiratory frequency, that can be influenced by sedatives, opiates, muscle relaxants, changes in chest wall compliance and intra - abdominal pressure (IAP) etc.
(Chen et al. 2011). Considering the facts given, the use of pressure-controlled regimes is tightly connected with continuous gas exchange monitoring, mainly $\mathrm{ETCO}_{2}$. $\mathrm{SpO}_{2}$, respiratory system mechanics measurement, eventually dead space to tidal volume ratio (VD/VT) measurement is also necessary.

There is substantial workload imposed on ICU staff regarding changes in ventilation parameters that require adjustment (Dojat et al. 1997). Modern ventilators have many servosystems that could be used in pressurecontrolled mode, e.g. ASV (adaptive support ventilation Bennet, USA) PRVC (pressure regulated volume control Maquet Gettinge) Germany, etc. (Manual_Bennett_840. 2015). All mentioned modes are representing only one specific ventilation regime and cannot be used on top of other pressure-controlled ventilation modes.

Considering these, we developed an extension method, that could be applied on top of all pressure controlled and assisted ventilation modes, named "Automatic proportional minute ventilation (APMV)"

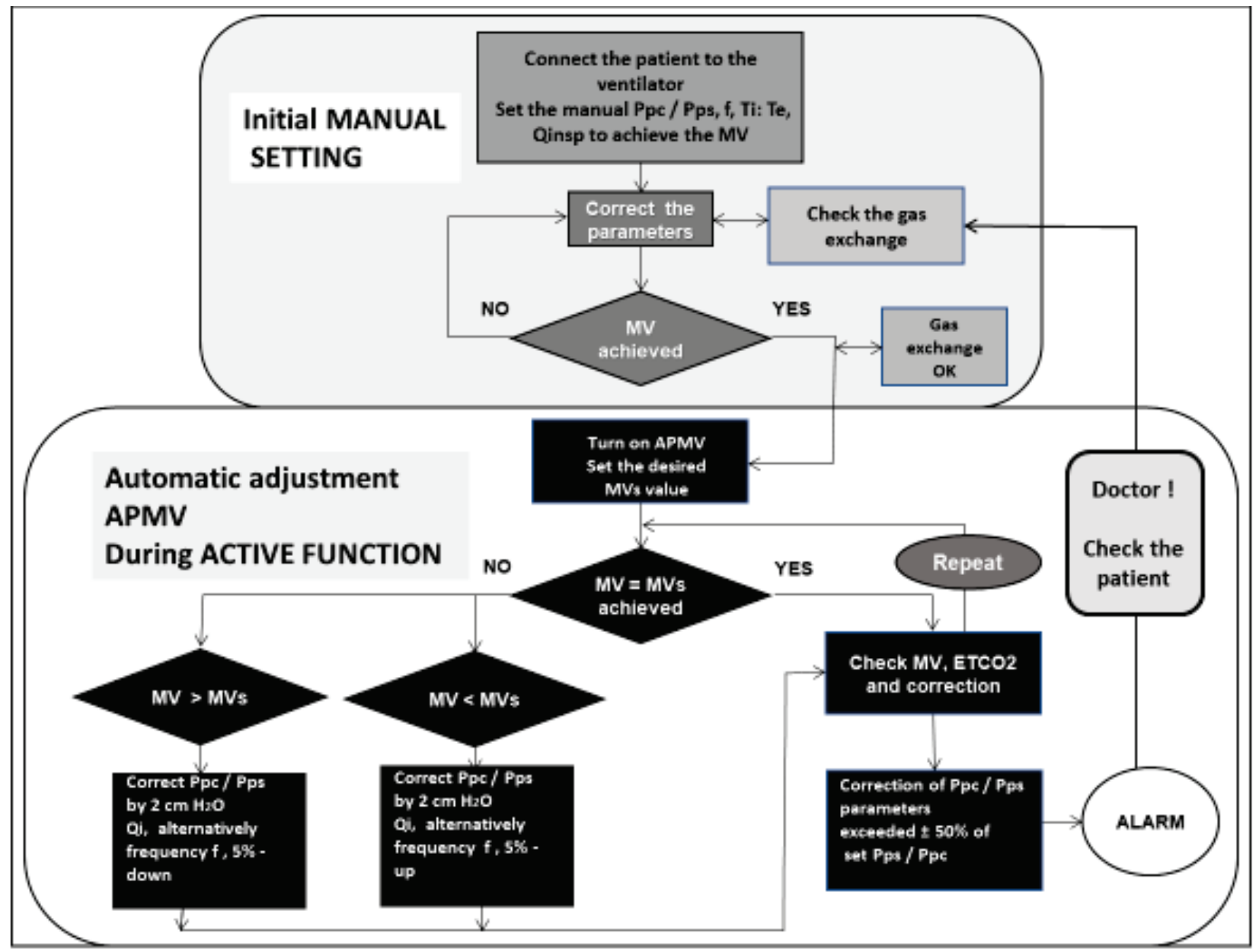

Fig. 1. Basic algorithm of APMV 
APMV is computer-assisted proportional autoadaptive ventilation method used over any pressure applied ventilation mode. Amount of ventilatory support that was set manually on the ventilator is adapting to the changes in respiratory system mechanics and ventilation drive in order to maintain an adequate minute ventilation and adequate gas exchange (Manual_Servoventilator AURA_V. 2017).

How does APMV work? The ventilator computer measures MV each 10-20 seconds and compares the value with MV set by the physician (minute ventilation servo (MVs). In case of decrease or increase of measured MV compared to MVs, computer adjusts MV by increasing or decreasing the pressure of pressure support/control (Pps/pc) $\pm 1-2 \mathrm{cmH}_{2} \mathrm{O}$ keeping $\mathrm{MV}$ and MVs equal. The regulation of changes of inspiratory pressure $\mathrm{Pps} / \mathrm{pc}$ is based on comparison of measured MV and targeted MVs. In order to maintain stable $\mathrm{ETCO}_{2}$ value throughout the postoperative weaning from the mechanical ventilation using APMV method, the ventilator can change MV up to a maximum of 1,5 times the MVs, which represents manually set MV by the physiacian. Further increase or decrease in MV by APMV is blocked by the software in order to prevent barotrauma or severe hypo/hyperventilation (Dojat et al. 2000, Gruber et al. 2008) and (Roubik et al. 2011).

If it is necessary to increase or decrease the pressure more than $\pm 50 \%$ to maintain $\mathrm{MV}$, the alarm is sound and physician's presence is required for parameters setting (Manual_Servoventilator_AURA_V. 2017, Török P et al. 2015).

Basic algorithm of APMV is explained in Fig. 1.

\section{Material and Methods}

Study was performed at Intensive Care Unit, East Slovakian Institute of Cardiovascular Diseases in Košice, Slovakia, between June 1. 2015 to December 31. 2016 and it was backed up by ethics committee approval by VÚSCH a. s. /EK No. VZ/7/KardO/2011/. All patients had their informed consents signed before they were enrolled in the study.

We created two groups of patients after CABG (coronary artery bypass grafting) that were ventilated with two different pressure-operated ventilation modes. The group 1 (APMV group, $n=40$ ) consisted of patients who were ventilated using PCV/PS controlled using APMV method. The second group of patients $(n=40)$ was ventilated by using pressure-controlled ventilation (PCV), and pressure supported ventilation (PS), manually set by the physician without APMV method.

Patients in both groups were selected from operating chart as follows: even patient numbers were enrolled in group 2 and odd patient number in group 1 e.g. APMV group. Exclusion criteria were LVEF less than $30 \%$, Chronic obstructive pulmonary disease (COPD) Gold stage III and IV, bronchial asthma, Chronic renal failure (CHRF) patients requiring haemodialysis. We were monitoring ventilation parameters, hemodynamics and gas exchange in the lung by monitor (CARESCAPE TM, B850, GE Healthcare USA). In group 1 we used PCV/PS with APMV method using servo-ventilator Chirolog Aura V (Chirana Medical a.s. Slovakia), and in group 2 we used PCV/PS mode using servo-ventilator Servo-I (Maquet group, Germany). Ventilation parameters were monitoring every 15 minutes during the first 2 hours since admission to ICU. Patients were not relaxed, only lightly sedated using $1 \%$ Propofol titration Richmond agitation and sedation score (RASS 2-0). After connecting patient to the ventilator, the MV has been set to $80-100 \mathrm{ml} / \mathrm{kg} \mathrm{IBV} / \mathrm{min}$, PEEP to 0.8-1.1 $\mathrm{cmH}_{2} \mathrm{O}$ for each $10 \mathrm{~kg}$ ideal body weight (IBV), but no less than 5 and no more than $10 \mathrm{~cm} \mathrm{H}_{2} \mathrm{O}$. PEEP was decreased only before weaning procedure at the end of ALV in both groups.

Table 1.

\section{Demographic data in group 1 (APMV) mean and \pm SD}

\begin{tabular}{lc}
\hline Number of patients & 40 \\
Average body weight $\pm S D(\mathrm{~kg})$ & $87 \pm 9.5$ \\
Age (year) & $62 \pm 7.9$ \\
Height $(\mathrm{cm})$ & $171 \pm 13$ \\
BSA body surface area $\left(\mathrm{m}^{2}\right)$ & $2.0 \pm 0.19$ \\
\hline
\end{tabular}

\section{Table 2.}

\section{Demographic data in group 2 (PCV/PS) mean and \pm SD}

\begin{tabular}{lc}
\hline Number of patients & 40 \\
Average body weight $\pm S D(\mathrm{~kg})$ & $89 \pm 9.1$ \\
Age (year) & $61 \pm 7.2$ \\
Height $(\mathrm{cm})$ & $169 \pm 15$ \\
BSA body surface area $\left(\mathrm{m}^{2}\right)$ & $2.0 \pm 0.12$ \\
\hline
\end{tabular}

No statistical difference between groups 1 and 2 in demographic data was observed. 
$\mathrm{MV}$ has been corrected to maintain $\mathrm{ETCO}_{2}$ in a range between $35-42 \mathrm{mmHg}$ for the first 10 minutes. The stability of MV was defined as the deviation of $\pm 5 \%$ in $\mathrm{ETCO}_{2}$ value. Then APMV method was implemented with MVs equal to patient's MV. Average Inspiratory fraction of oxygen $\left(\mathrm{FiO}_{2}\right)$ was between $0.45 \pm 0.05$ in both groups in order to obtain $\mathrm{SpO}_{2}$ at least $94 \%$. There was no need to change $\mathrm{FiO}_{2}$ during measurement. Ventilation frequency has been set to $16.5 \pm 2$ breaths/min calculated according to the pattern: $\mathrm{f}=\mathrm{INT}(21-\mathrm{IBW}(\mathrm{kg})) / 17)$.
Specific tidal volume (VTs) ranged from 4.9-5.9 $\mathrm{ml} / \mathrm{kg}$ IBV. Demographic data of both groups are showed in Table 1. and 2.

Statistical evaluation compared group 1 and 2 in demographic data, ventilation parameters describing the changes in ventilation, ventilator parameters settings, respiratory system mechanics, hemodynamic parameters and nurse and doctor time spent with ventilator were performed by the two-tail dependent Student's t-test and linear correlation.

Table 3. Change in average ventilatory parameters in group 1 in $0,45,60,90,120$ minutes from the onset of ALV

Average ventilation parameters $($ mean \pm SD) $(n=40)$ in group No.1 - PS - APMV

\begin{tabular}{lccccc}
\hline Parameters Time (min) & 0 & 45 & 60 & 90 & 120 \\
Measured $\mathrm{MV}\left(l^{*} \mathrm{~min}^{-1}\right)$ & $7.12 \pm 1.8$ & $7.2 \pm 1.5$ & $7.5 \pm 1.5$ & $7.2 \pm 1.9$ & $7.7 \pm 1.4$ \\
Breathing frequency $f\left(\mathrm{c}^{*} \mathrm{~min}^{-1}\right)$ & $15.5 \pm 0.5$ & $15.5 \pm 0.5$ & $15.5 \pm 0.5$ & $18 \pm 2.8$ & $17 \pm 2.2$ \\
$\mathrm{PEEP}\left(\mathrm{cm} \mathrm{H}_{2} \mathrm{O}\right)$ & $8 \pm 1$ & $8 \pm 1$ & $8 \pm 1$ & $4 \pm 1$ & $4 \pm 0.5$ \\
$\mathrm{FiO}_{2}$ & $0.43 \pm 0.03$ & $0.43 \pm 0.03$ & $0.43 \pm 0.03$ & $0.43 \pm 0.03$ & $0.43 \pm 0.03$ \\
$\mathrm{Pps} /$ Ppc driving pressure $\left(\mathrm{cm} \mathrm{H}_{2} \mathrm{O}\right)$ & $11 \pm 1.3$ & $12 \pm 1.5$ & $12 \pm 1.5$ & $10 \pm 2$ & $8 \pm 1$ \\
Trigger activity & No & No & No/Yes & Yes & Yes \\
\hline
\end{tabular}

Table 4. Change in average ventilatory parameters in group 2 in $0,45,60,90,120$ minutes from the onset of ALV

Average ventilation parameters $($ mean $\pm \mathrm{SD})(\mathrm{n}=40)$ in group No.2 - PCV/PS

\begin{tabular}{lccccc}
\hline Parameters Time (min) & 0 & 45 & 60 & 90 & 120 \\
Measured $\mathrm{MV}\left(l^{*}\right.$ min $\left.^{-1}\right)$ & $7 \pm 1.4$ & $6.4 \pm 1.1$ & $7.4 \pm 1.7$ & $7.4 \pm 1.6$ & $8 \pm 1.2$ \\
Breathing frequency $f\left(c^{*}\right.$ min $\left.^{-1}\right)$ & $14.5 \pm 0.5$ & $15.5 \pm 0.5$ & $14.5 \pm 0.5$ & $18 \pm 2.2$ & $18 \pm 2.0$ \\
$P E E P\left(\mathrm{~cm} \mathrm{H} \mathrm{H}_{2} \mathrm{O}\right)$ & $8 \pm 1$ & $8 \pm 1$ & $8 \pm 1$ & $6 \pm 1$ & $4 \pm 0.5$ \\
$\mathrm{FiO}_{2}$ & $0.45 \pm 0.05$ & $0.45 \pm 0.05$ & $0.45 \pm 0.05$ & $0.45 \pm 0.05$ & $0.45 \pm 0.05$ \\
Pps/Ppc driving pressure $\left(\mathrm{cm} \mathrm{H}_{2} \mathrm{O}\right)$ & $10 \pm 1$ & $13 \pm 2.1$ & $13 \pm 1.9$ & $10 \pm 0.8$ & $9 \pm 2$ \\
Trigger activity & No & No & No/Yes & Yes & Yes \\
\hline
\end{tabular}

\section{Results}

Average ventilation parameters used in groups 1 and 2 respectively are showed in Table 3 and 4 . Results are presented as a mean value \pm standard deviation (SD). The statistical significance of the differences or changes in results was calculated using the two-tail dependent Student's t-test and linear correlation.

The average duration of postoperative artificial ventilation including using T-piece was $3.1 \pm 1.3$ hours in group 1 vs. $3.3 \pm 1.4$ hours in the group $2(p=N S)$. After $1.4 \pm 0.5$ hours when patient's start breathing, trigger was the main control element of ventilation. Because after activation of spontaneous ventilation trigger is regarding to ventilation volume usually iregular. The APMV method regulated each separate ventilation volumes by changes of $\mathrm{Pps} / \mathrm{Ppc}$, that requested minute ventilation to be achieved.

A patient has been shifted to PS mode in both groups. We compared the deviations in minute ventilation (MV) from target value (MVs), which was not statistically significant ( $\mathrm{p}=\mathrm{NS}$ ) between group 1 and 2 . We observed statistically significant difference between MV and MVs in group 2 in 30, 45 and 120 minutes from 
the onset of artificial lung ventilation $(p<0.01)$. Therefore, manually adjustment of $\mathrm{Ppc} / \mathrm{Pps}$ was necessary to maintain targeted MV. Stability of MV was statistically significantly better in group $1(\mathrm{p}<0.01)$, no manual adjustment was necessary see Fig. 2 and Fig. 3. We considered MV to be adequate if deviation in $\mathrm{ETCO}_{2}$ value was $\pm 5 \%$ (mmHg) continuously measured by capnometer.

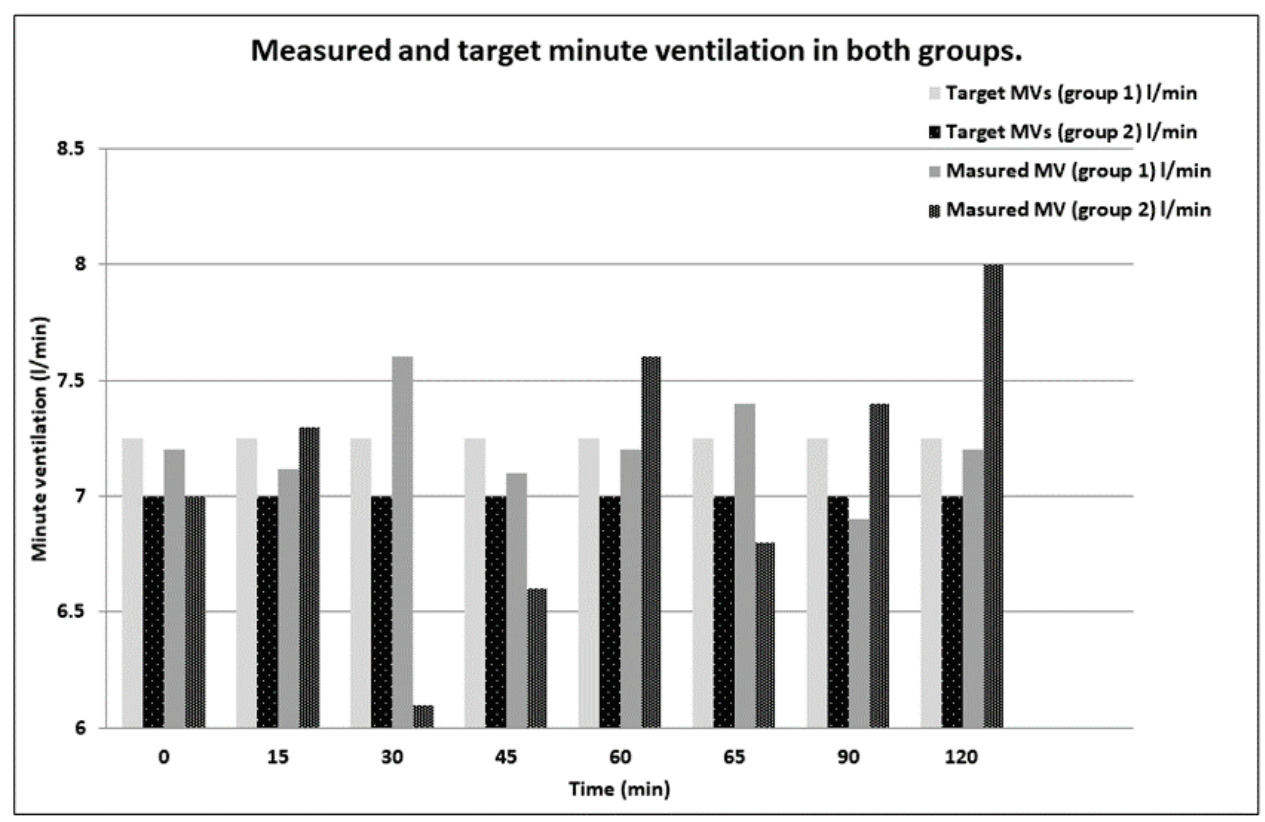

Fig. 2. Present measured and target average values in group 1 and 2 of parameters MV and MVs. Measured MV in group 2 showed far higher differences compared with group 1.

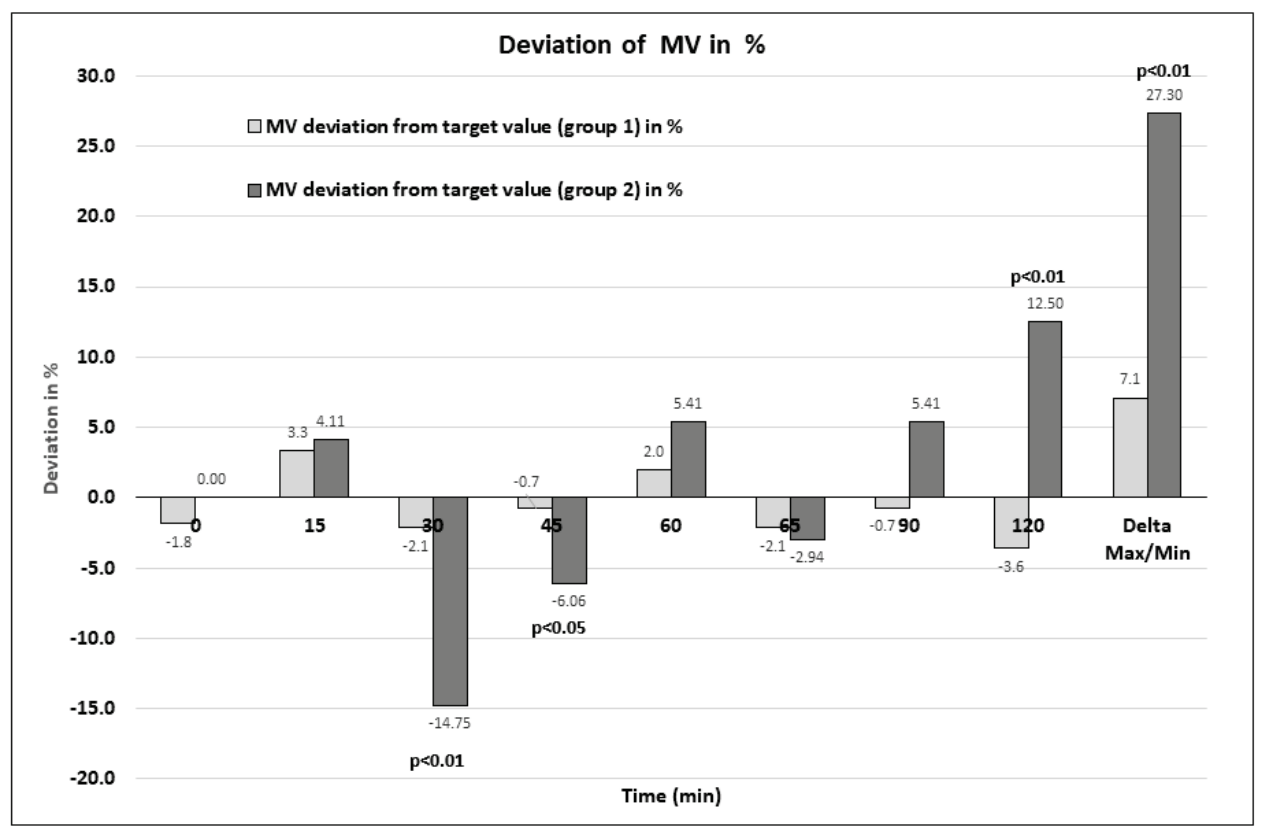

Fig. 3. Showed deviation of MV in percentage (\%). We can see that MV in group 1 is more stable $(+3.6$ to $4.1 \%)$ compared with group 2. (-14.8 to $12.5 \%),(p<0.01)$.

\section{Discussion}

We used PCV/PS ventilation mode with new APMV method and compared with manually set ventilator parameters in PCV/PS ventilation mode. To our best knowledge this is a first work with this approach in ventilation area. There are changes in MV and VT caused by change in respiratory system mechanics and because of resuming of spontaneous ventilation activity. APMV automatically corrects problems with instability in mechanical ventilation (changes in respiratory system mechanics, changing respiratory drive of the patient). Ventilation parameters in non-APMV (PCV/PS) group must be corrected manually by the staff, whereas in 
AMPV group, MV is corrected itself by APMV algorithm. APMV algorithm maintained MV very close to physicians demanded MVs. We applied intelligent system regarding APMV that changes pressure support in each extent, thus amount of flow, mainly peak flow (Q), as well as ventilation frequency.

Comparison of APMV method and manually set parameters by staff showed a greater stability in gas exchange in patients ventilated with APMV. This can be also seen in variation of $\mathrm{ETCO}_{2}$. Changes in respiratory
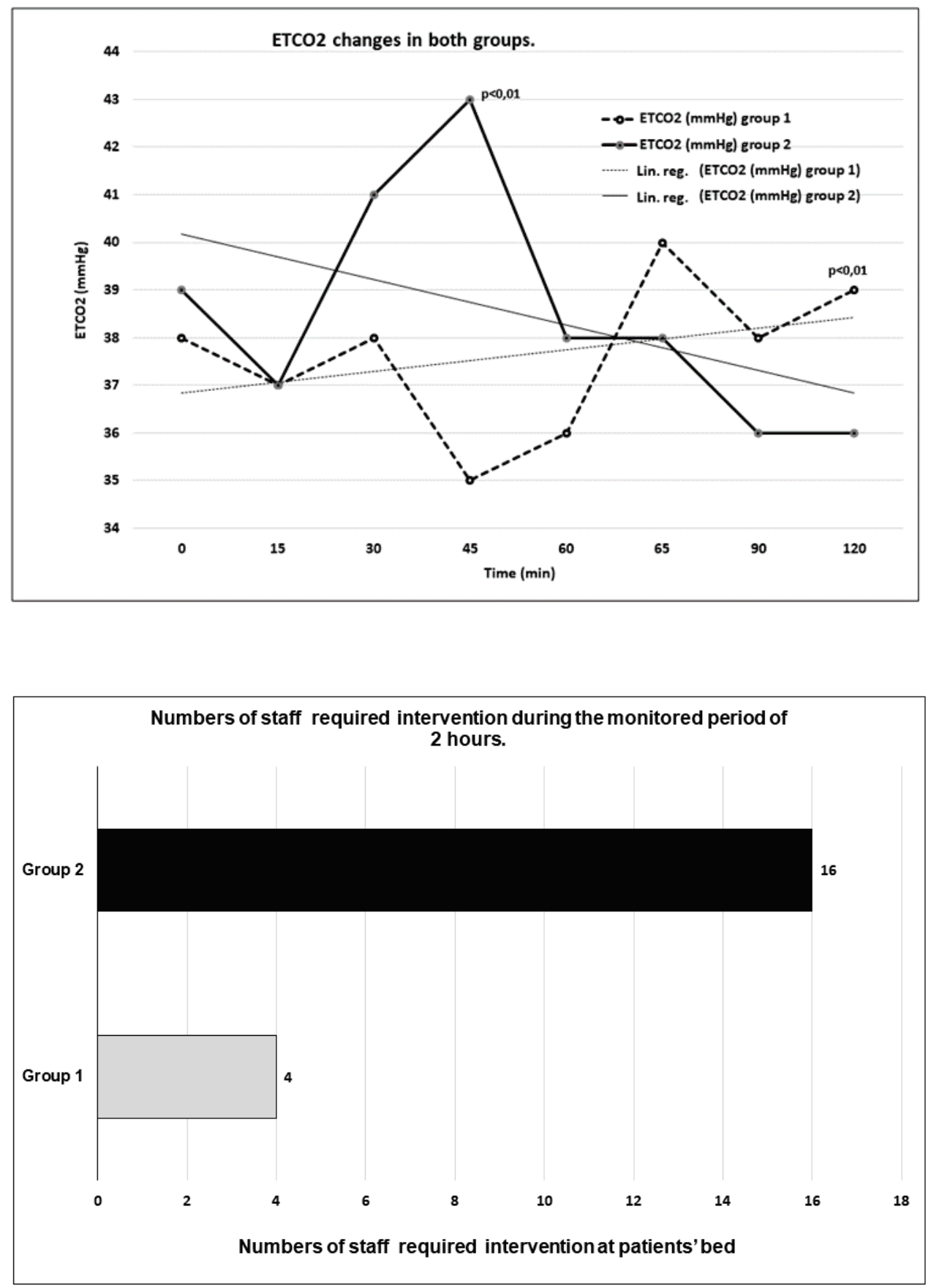

Fig. 4. Shows differences in average of $\mathrm{ETCO}_{2}$ value between groups 1 and 2 . The difference up to 30 minutes of ventilatory onset was not statistically significant (38 $4 \mathrm{mmHg}$ vs $39 \pm 7.5$ ). After 45 minutes from onset of ventilation, difference was up to $8 \mathrm{mmHg}$ between both groups $(p<0.01)$ t-test. This mean, that gas exchange in group 1 was more stable compare with group 2. Group 1 linear regresion showed increasing trend of $\mathrm{ETCO}_{2}$ and in group 2 decreasing trend of $\mathrm{ETCO}_{2}$, while both are in acceptable range.

Fig. 5. Shows the number of events, (with artificial ventilation related intervention), which required staff to come to patients in whole group 1 and 2. 4 times often intervention of nurses and doctors was needed in group 2 compare with group 1 In group 1 no one of 4 interventions was related to ventilation parameters changes (the reason was alarm range setting, trigger sensitivity setting, and patients' physiological requirements). $\mathrm{PaO}_{2} /$ $\mathrm{FiO}_{2}$ was $309 \pm 18 \mathrm{mmHg}$ in group 1 and $305 \pm 10 \mathrm{mmHg}$ in group $2(p=N S)$. Static pulmonary compliance (Cst) in first and last hour of ventilation was $41 \pm 10$ to $49 \pm 13 \mathrm{ml} . \mathrm{cm} \mathrm{H}_{2} \mathrm{O}^{-1}$ in group 1 vs. $42 \pm 7$ to $48 \pm 15 \mathrm{ml} . \mathrm{cm}$ $\mathrm{H}_{2} \mathrm{O}^{-1}$ in group $2(p=N S)$. We didn't find any statistically significant difference in airway resistance (Raw), that was $3.1 \pm 0.44 \mathrm{cmH}_{2} \mathrm{O}^{-1} \mathrm{I}^{-1} \mathrm{~s}^{-1}(\mathrm{P}=\mathrm{NS})$. After resuming of spontaneous ventilation in PSV mode, the respiratory frequency was $15.5 \pm 2.9$ breaths/min and $16 \pm 3.1$ breaths/min in group 1 and 2 respectively ( $p=N S$ ).

system mechanics occur very frequently in mechanically ventilated patients. This could lead to hypoventilation, hyperventilation or ventilation asynchrony during either pressure support (PS) ventilation or pressure-controlled ventilation (PCV) modes (Arnal et al. 2013, Clavieras et al. 2013, Grasso et al. 2000, Tonetti et al. 2017, Török 
et al. 2017). With constant pressure support, changes in respiratory system mechanics in terms of decrease in compliance or increase in resistance require change of ventilation frequency in order to maintain the MV (Török P et al. 2015, Török P et al. 2001). Changes in respiratory system mechanics also present with changes in time constants of different lung compartments that can lead to worsening in lung gas distribution homogeneity (Gruber et al. 2008) (Candik et al. 2018). Changes in $\mathrm{PaCO}_{2}$ $\left(\mathrm{EtCO}_{2}\right)$ were, using APMV method, much lower due to better stability in minute ventilation (Manual_Servoventilator_AURA_V. 2017).

Experimental studies (Campbell et al. 2002, Török P et al. 2017) show that respiratory frequency is compensatory increased whenever there is a decrease in compliance. The same relationship has been shown in experiment work (Arnal et al. 2013, Dojat et al. 2000) where changes in VT were compared regarding to respiratory system mechanics by using PS vs ASV (adaptive supporting ventilation) ventilation mode. In PS mode it has been shown a decrease in both VT and MV, while the same substantial decrease of VT and MV was present in ASV ventilation mode. The ASV mode is compensating $\mathrm{MV}$ by the ventilator. In comparison with APMV method which is not ventilation mode per se. APMV method could be used as a universal extension for all pressure-based ventilator modes. Other ventilator modes operate similarly however, they represent individual ventilatory modes and do not allow the advantages of proportional regulation in these pressurebased ventilatory modes (Manual_Bennett_840. 2015).

We used two types of ventilators (Aura V and Servo I Maquet) which in pressure controlled regimes are identical according to ISO standard. In group 1 we used only ventilator Aura V with APMV method because only this one machine was equipped with APMV regulation method.

\section{Conclusion}

Presented results suggest that MV regulation by automatic proportional minute ventilation (APMV) method is more precise regarding to deviation of $\mathrm{MV}$ and $\mathrm{ETCO}_{2}$. The staff time spent with ventilator in AMPV was 4 times shorter than in group 2. APMV seems feasible idea for achieving better stabilization of controlled or supported ventilation. APMV method could be used as an extension on top of all pressure-based ventilation modes (pressure-controlled ventilation - PCV, pressure support - PS, synchronized intermittent mandatory ventilation - SIMV-p, bilevel ventilation BiPAP, etc.

\section{Conflict of Interest}

There is no conflict of interest.

\section{References}

ARNAL J-M, GARNERO A, NOVONTI D, DEMORY D, DUCROS L, BERRIC A, DONATI S, CORNO G, JABER S, DURAND-GASSELIN J: Feasibility study on full closed-loop control ventilation (IntelliVent-ASVTM) in ICU patients with acute respiratory failure: a prospective observational comparative study. Critical care (London, England) 17: R196-R196, 2013. https://doi.org/10.1186/cc12890

CAMPBELL RS, DAVIS BR: Pressure-controlled versus volume-controlled ventilation: does it matter? Respir Care 47: 416-424; discussion 424-426, 2002.

CANDIK P, RYBAR D, DEPTA F, SABOL F, KOLESAR A, GALKOVA K, TOROK P, DONICOVA V, IMRECZE S, NOSAL M, DONIC V: Relationship between dynamic expiratory time constant tau(edyn) and parameters of breathing cycle in pressure support ventilation mode. Physiological Research 67: 875-879, 2018. https://doi.org/10.33549/physiolres.933750

CLAVIERAS N, WYSOCKI M, COISEL Y, GALIA F, CONSEIL M, CHANQUES G, JUNG B, ARNAL JM, MATECKI S, MOLINARI N, JABER S: Prospective randomized crossover study of a new closed-loop control system versus pressure support during weaning from mechanical ventilation. Anesthesiology 119: 631-641, 2013. https://doi.org/10.1097/aln.0b013e3182952608

DOJAT M, HARF A, TOUCHARD D, LEMAIRE F, BROCHARD L: Clinical evaluation of a computer-controlled pressure support mode. Am J Respir Crit Care Med 161(4 Pt 1): 1161-1166, 2000. https://doi.org/10.1164/ajrccm.161.4.9904064 
DOJAT M, PACHET F, GUESSOUM Z, TOUCHARD D, HARF A, BROCHARD L: NeoGanesh: a working system for the automated control of assisted ventilation in ICUs. Artif Intell Med 11: 97-117, 1997. https://doi.org/10.1016/s0933-3657(97)00025-0

GRASSO S, PUNTILlO F, MASCIA L, ANCONA G, FIORE T, BRUNO F, SLUTSKY AS, RANIERI VM: Compensation for increase in respiratory workload during mechanical ventilation. Pressure-support versus proportional-assist ventilation. Am J Respir Crit Care Med 161: 819-826, 2000. https://doi.org/10.1164/ajrccm.161.3.9902065

GRUBER PC, GOMERSALL CD, LEUNG P, JOYNT GM, NG SK, HO KM, UNDERWOOD MJ: Randomized controlled trial comparing adaptive-support ventilation with pressure-regulated volume-controlled ventilation with automode in weaning patients after cardiac surgery. Anesthesiology 109: 81-87, 2008. https://doi.org/10.1097/aln.0b013e31817881fc

CHEN CW, WU CP, DAI YL, PERNG WC, CHIAN CF, SU WL, HUANG YC: Effects of implementing adaptive support ventilation in a medical intensive care unit. Respir Care 56: 976-983, 2011. https://doi.org/10.4187/respcare.00966

MANUAL_BENNETT_840. Operating Instructions: Bennett 840 ventilator. 2015.

MANUAL_SERVOVENTILATOR_AURA_V. Operating Instructions: Servoventilator AURA V. 2017.

ROUBIK K, PACHL J, ZABRODSKY V: Normocapnic high frequency oscillatory hyperventilation increases oxygenation in pigs. Physiol Res 60: 749-755, 2011.

TONETTI T, VASQUES F, RAPETTI F, MAIOLO G, COLLINO F, ROMITTI F, CAMPOROTA L, CRESSONI M, CADRINGHER P, QUINTEL M, GATTINONI L: Driving pressure and mechanical power: new targets for VILI prevention. Ann Transl Med 5: 286, 2017. https://doi.org/10.21037/atm.2017.07.08

TÖRÖK P, ČANDÍK P, SALADIAK S, RYBÁR D, IMRECZE Š, KOLESÁR A: Basic principles of autoadaptive modes and "automatic proportional minute ventilation of lungs" SSAIM: 154-158, 2015.

TÖRÖK P, DONIČ V, NOSÁL' M, RYBÁR D, SALADIAK S, SABOL F, KOLESÁR A, JANKAJOVÁ M, GALKOVÁ K: Individualized adjustment of artificial lung ventilation parameters, such as prevention of lung parenchymal trauma. Anaesthesiol Intens Med 6: 72-76, 2017.

TÖRÖK P, MÁJEK M, KOLNÍK J: Is the Time Constant „Tau (t)“ in ALV constant? Anaesthesiol Intens Med 6: 291-297, 2001. 